\title{
Changing of the Guard: Tips for Enabling Smooth Officer Transitions
}

\author{
Monika Ingalls \\ Dr. Elizabeth Hill, University of Minnesota Duluth
}

Dr. Hill is focused on active learning teaching methods and materials research. After receiving her Ph.D. from the Georgia Institute of Technology, Dr. Hill spent several years working industrially.

\section{Ms. Helene Finger P.E., California Polytechnic State University, San Luis Obispo}

Helene Finger has been a faculty member in the Civil/Environmental Engineering Department at Cal Poly, San Luis Obispo since 1997, with a break from 2007-2010 to pursue her PhD in Mechanical Engineering focusing on computational science and engineering and thermo-fluid sciences. At Cal Poly, she teaches courses in Water Resources and Water Quality. In 2000, she took on the additional roles of Director of the Women's Engineering Program and advising the Cal Poly section of the Society of Women Engineers.

\section{Dr. Marca J. Lam, Rochester Institute of Technology (COE)}

Dr. Marca Lam is a senior lecturer at RIT. She received her B.S. (summa cum laude) and M.S. in Mechanical Engineering from the University at Buffalo, and her Ph.D. from Virginia Tech. Dr. Lam's specialty is in vibrations and control. She teaches a variety of courses to both graduate and undergraduate students, such as a 3-D graphics course, materials science, system dynamics, and optimal design.

Dr. Lam is the faculty advisor for the Society of Women Engineers (SWE) and an executive board member for WE@RIT. She received the SWE Outstanding Faculty Advisor of the Year Award in 2015. She is active in the SWE Rochester Section, where she holds to position of president. Dr. Lam also serves as an advocate for the KGCOE Honors Program, and is the main lead for the second year curriculum. Dr. Lam is actively involved as associate organizer for RIT-hosted Mini-Baja competition.

\section{Dr. Gloria Guohua Ma, Wentworth Institute of Technology}

Gloria Ma is an Associate Professor in the Department of Mechanical Engineering and Technology. She has been teaching robotics with Lego Mindstorm to ME freshmen for several years. She is actively involved in community services of offering robotics workshops to middle- and high-school girls. Her research interests are dynamics and system modeling, geometry modeling, project based engineering design, and robotics in manufacturing.

\section{Dr. Diane L. Peters, Kettering University}

Dr. Peters is an Assistant Professor of Mechanical Engineering at Kettering University.

Prof. Stephanie G Wettstein, Montana State University, Montana Engineering Education Research Center

Stephanie Wettstein is an Assistant Professor in the Chemical and Biological Engineering department at Montana State University in Bozeman, MT. She has been the faculty advisor of the MSU SWE chapter since 2013.

\section{Dr. Deborah S. Won, California State University, Los Angeles}

Deborah Won is an Associate Professor in Electrical and Computer Engineering at California State University, Los Angeles. Her specialization is in Biomedical Engineering and her scientific research area focuses on neuro-rehabilitative technology. Her educational research interests include use of Tablet PCs and technology to better engage students in the classroom as well as pedagogical and advisement approaches to closing the achievement gap for historically under-represented minority groups.

Dr. Claudia Mara Dias Wilson, New Mexico Institute of Mining and Technology 


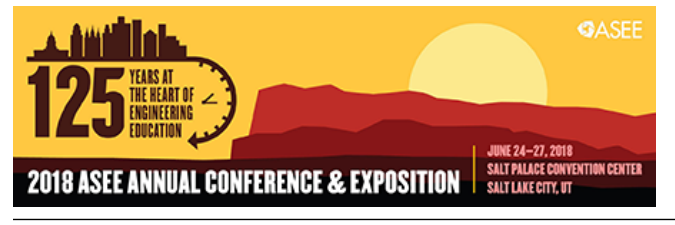

Dr. Claudia Mara Dias Wilson is an Associate Professor in civil engineering at the New Mexico Institute of Mining and Technology (New Mexico Tech). She earned her Bachelor's, Master's and Ph.D. degrees from the Florida State University. Although she specialize in earthquake mitigation and the development of control algorithms for semi-active dampers to reduce seismic vibrations on buildings, her research interests are broad and include topics in structural engineering, earthquake engineering, construction management, transportation engineering, and engineering education. She also advises the Student Chapters of the Society of Women Engineers (SWE) and the American Society of Civil Engineers (ASCE) at New Mexico Tech.

\section{Cheyenne Florenia Rivera}

Ms. Emily Silva, California State University, Los Angeles

Tara Sundsted, Montana State University- Bozeman 


\title{
Changing of the Guard: Tips for Enabling Smooth Officer Transitions
}

\begin{abstract}
Many campuses throughout the nation have active sections of the Society of Women Engineers (SWE). In an effective section, the SWE officers work together as a team to plan, organize, and carry out a host of activities ranging from mentorship networks, career talks, middle school outreach events, and fundraisers. The team effort of these officers can make a substantial impact on the perception of and support for women in Engineering at a school and surrounding community if the officers are enabled from the beginning of the year to do so. These officer positions themselves, commonly consisting of President, Vice President, Treasurer, Secretary, Event Coordinator, and Historian can provide meaningful and valuable leadership opportunities in a well functioning section. However, many sections struggle for much of the first semester organizing themselves and getting activities up and off the ground because the proverbial baton is dropped. Because the duties are generally the same for each officer from year to year and the procedures that each officer needs to follow tend to change incrementally from year to year, it makes sense to establish a system for training the new incoming officers before they officially take office to ensure a smooth transition. In this paper, the common challenges that SWE sections face during the "changing of the guard" are presented along with some tips on how to achieve such a smooth transition, backed by examples of systems that some of those very active and productive SWE sections have established and follow to make office transition a smoother process and to enable them to hit the ground running at the start of the academic year.
\end{abstract}

\section{Introduction}

Campuses throughout the nation support student led pre-professional organizations. There are many factors that ensure a successful student club. Evans et. al [1] presented seven keys to establishing a successful American Society of Civil Engineering (ASCE) student chapter or club: active members, holding regular/professional meetings, participating in regional/national organization student activities, sponsoring and participating in social activities, hosting and participating in local professional organization events, and performing outreach activities. All of these principles apply to other pre-professional clubs. Frieze and Blum [2] emphasized that an active Student Advisory Council enabled the success of the student club in Computer Science at Carnegie Mellon University. The Student Advisory Council is composed of representatives from all four years of the undergraduate level and members from the graduate programs. Eight factors have been identified as critical to creating an active student club, including: outstanding student leaders, younger member involvement, support from the institution, active program, attending activities away from campus, active practitioner advisor, active advisor, and adequate funds and fund raising activities [3].

However, given the dependence of success on a strong leadership team to implement activities in accordance with the principles laid out above, a robust leadership transition from year to year is imperative for the advancement of these organizations. Conversely, the annual rotation of officers and a weak handoff of roles and duties from the "old guard" to the "new guard" poses challenges to an organization's success for the year. Through the process of "changing of the guard", the organization gains the solid foundation needed to be successful in the upcoming year 
[4]. The National Association of Campus Activities defines effective leadership transition as: "the process by which past and future student leaders in an organization work together to review and learn from previous events and programs and prepare for the upcoming year." [4]. This paper investigates leadership transitions in six different Student Sections of the Society of Women Engineers (SWE) to determine best practices for different size sections.

The SWE student sections aim to "stimulate women to achieve full potential in careers as engineers and leaders, expand the image of the engineering profession as a positive force in improving the quality of life, demonstrate the value of diversity." Student officers work together as a team to plan, organize, and carry out a host of activities ranging from mentorship networks, career talks, middle school outreach events, and fundraisers. The team effort of these officers can make a substantial impact on the support and the perception of engineering students at a school and within the surrounding community. However, many groups struggle for much of the first semester each year to organize themselves and get activities up and off the ground because the proverbial baton has been dropped. Because the duties are generally the same for each officer from year to year, to ensure a smooth transition, it makes sense to establish a system for training the incoming officers before they officially take office.

This paper presents the "changing of the guard" chronological pattern of organization followed by six different student sections of the Society of Women Engineers. Because these procedures vary depending on the size of the student section, they were divided in three categories: large, medium, and small sections. Through case studies, this paper exemplifies successful officer transitions and provides current engineering students and their faculty mentors organization and communication tips to enhance transitional periods in engineering student pre-professional clubs, sections, chapters or societies.

\section{Case Study Approach}

Data were collected from six SWE sections of different sizes. All of these sections reported to be very active within their institutions and their communities, and most importantly; they all had smooth officer transitions.

The following information were collected from each institution:

- Description of SWE officer transition process

- Undergraduate enrollment at the institution

- Number of women majoring in engineering disciplines

- Number of active (paying) SWE members in the section

- Number of officers and a description of their roles

- Average number of students (SWE members or otherwise) participating in section events

- Age of SWE section at each institution

- Time at which officer transitions started to go smoothly

\section{Results}


A summary of the numerical information collected from each participating institution is presented in Table 1. The size of the institutions as well as the numbers of members and officers in each of the six SWE sections varied considerably. While some SWE sections had as many as 400 members and 37 officers (Cal Poly), others had only 14 members and 5 officers (NMT). As expected, procedures that proved effective in large sections could not be implemented in small ones, and vice versa, due to the considerable difference in number of members and officers. For this reason, the six participating institutions were grouped in the following three categories: large (more than 50 members), medium (20 to 50 members), and small (less than 20 members) sections. A summary of their leadership structures and their transitioning procedures are presented below.

Table 1 - Summary of data collected

\begin{tabular}{|c|c|c|c|c|c|c|}
\hline Institutions & $\begin{array}{c}\text { Number of } \\
\text { Undergraduate } \\
\text { students }\end{array}$ & $\begin{array}{c}\text { Number of } \\
\text { women } \\
\text { majoring in } \\
\text { engineering }\end{array}$ & $\begin{array}{c}\text { Number } \\
\text { of Paid } \\
\text { SWE } \\
\text { members }\end{array}$ & $\begin{array}{c}\text { Number } \\
\text { of SWE } \\
\text { officers }\end{array}$ & $\begin{array}{c}\text { Number of } \\
\text { students } \\
\text { attending } \\
\text { regular } \\
\text { meetings }\end{array}$ & $\begin{array}{c}\text { Number of } \\
\text { students } \\
\text { participating } \\
\text { in SWE } \\
\text { events }\end{array}$ \\
\hline $\begin{array}{c}\text { California State } \\
\text { University, Los } \\
\text { Angeles } \\
\text { (CalStateLA) }\end{array}$ & $\sim 28,000$ & 485 & 54 & 11 & $10 \sim 15$ & $10 \sim 20$ \\
\hline $\begin{array}{c}\text { California } \\
\text { Polytechnic State } \\
\text { University, San } \\
\text { Luis Obispo (Cal } \\
\text { Poly) }\end{array}$ & 21,000 & 1762 & 400 & 37 & 60 & $30 \sim 80$ \\
\hline $\begin{array}{c}\text { Montana State } \\
\text { University (MSU) }\end{array}$ & 15,000 & 712 & 37 & 9 & $5 \sim 12$ & $10 \sim 20$ \\
\hline $\begin{array}{c}\text { Wentworth } \\
\text { Institute of } \\
\text { Technology } \\
\text { (WIT) }\end{array}$ & 3,977 & 330 & 25 & 10 & 25 & 20 \\
\hline $\begin{array}{c}\text { Kettering } \\
\text { University (KU) }\end{array}$ & 1900 & 323 & 16 & 7 & 20 & 20 \\
\hline $\begin{array}{c}\text { New Mexico } \\
\text { Institute of } \\
\text { Mining and } \\
\text { Technology } \\
\text { (NMT) }\end{array}$ & 1569 & 198 & 14 & 5 & $7 \sim 14$ & $7 \sim 14$ \\
\hline
\end{tabular}

\section{Organization of SWE Sections}

Large Section (Cal Poly) 
Cal Poly SWE (CPSWE)'s leadership structure mimics that of a company where the President oversees the Vice Presidents of different departments and other higher-level positions. Each Vice President oversees a core of approximately 5-9 officers who plan valuable networking and outreach events and spread the SWE mission and objective. CPSWE has four cores: Outreach, Corporate, Membership, and Public Relations. The cores, although unique in their responsibilities, must work together to plan events and support SWE members. This structure fosters a legacy of leadership and an opportunity to grow one's passion and professional skills. CPSWE consists of 37 total officers. The officer positions and their corresponding descriptions are outlined below.

\section{$\underline{\text { Executive Officers }}$}

- President- Oversee all SWE activities and executive core, run officer meetings

- Vice Presidents (4) - Oversees all cores and serves as a liaison between Executive Core and their responsible core (Outreach, Corporate, Membership, and Public Relations).

- Secretary - Organizes national and regional conference attendances and oversee the maintenance of the SWE Office.

- Treasurers (2) - Monitors the club's flow of expenses and income.

\section{Community Outreach Core}

- Outreach Assistant- Recruits Outreach Committee members as subcommittee coordinators and submits Outreach Metric Tool for all outreach events.

- Elementary Outreach Chair- Organizes Girl Scout Day, Fourth Grade Days, and special requested outreach events for elementary school students.

- Middle School Outreach Chair- Organizes Build an Engineer Day, and special requested outreach events for middle school students.

- High School Outreach Chair- Organizes SWE Welcome, SWE-EETY, and special requested outreach events for high school students.

- Robotics Outreach Chair- Organizes VEX Robotics Competition, Build-a-Bot, and special requested outreach events for the robotics community.

- Community College Outreach Chair- Coordinate with local community colleges and organizes special requested outreach events for community college students.

- SWENext Chair- Collaborates and mentors all SWENext clubs in CPSWE's network, organizes SWENext Leadership Training Conference, and special requested outreach events for SWENexters.

\section{Corporate Relations Core}

- Corporate Relations Assistant- Maintains corporate database and leads corporate committee.

- Scholarship Director- Coordinates scholarships to hand out at Evening With Industry, prepares scholarship materials for Corporate Committee to read, advertises all scholarships, and maintains scholarship accounts.

- Meetings Director- Coordinates speakers, food, and gifts for CPSWE general meetings and plans meeting topics and joint meetings with other campus clubs. 
- Evening with Industry (EWI) Corporate Director- Contacts industry members to sponsor tables for EWI and tracks Ewi payments.

- Evening with Industry (EWI) Events Director- Plans all details of EWI related to reserving the location, decorations, creating the program, delegate duties to Corporate Committee members.

- Team Tech Directors (2)- Finds a corporate partner and project for Team Tech, organizes project and volunteers, and organizes and runs design reviews, and Team Tech meetings

\section{Public Relations Core}

- Public Relations Assistant- Compiles and sends weekly SWEmail to members and assists VP with advertising tasks.

- Graphics Director- Designs flyers for events and SWE newsletter for members and Cal Poly student body.

- Webmaster- Maintains CPSWE website, Twitter account, and website calendar.

- Historian- Compiles scrapbook of SWE events for the year and ensures photo documentation of events.

- Department/Club Relations Director- Represents SWE to all clubs and departments meetings and events.

\section{Member Relations Core}

- Member Relations Assistant- Assists VP in membership related tasks.

- WOW, eWeek, \& Open House Director- Works with Engineering Student Council to plan eWeek events during National Engineers Week and plans events for WOW and Open House.

- Freshmen Director- Pair Bigs/Littles program for incoming freshmen and plan events for the year and coordinates announcements in freshmen classes about SWE.

- Diversity Director- Coordinates events with clubs on campus that promote diversity in engineering and on the Cal Poly campus.

- Member Retention Director- Coordinates new and renewed members and analyzes member survey.

- Freshmen Representatives (3)- Works closely with each core to provide a voice to freshmen students.

- Transfer Representatives- Work closely with Diversity Director to increase involvement of transfer students in SWE

\section{Medium Section (CalStateLA/MSU/WIT)}

Medium sections have 9 to 11 officers and less than 50 members in the SWE section. The officers include: president, vice-president, secretary, treasurer, outreach coordinator/chair, event coordinator/chair, public relations, and conference coordinator/chair, and alumni associations. In brief, each officer's key roles and responsibilities are: 
- President: oversees the club, is the key point of contact for the faculty advisor and meets regularly with them, interacts with the Region leadership, manages most fundraising efforts, and runs weekly meetings.

- Vice-president: assists the president in all her duties, as well as takes own her own individual tasks such as fundraising.

- Secretary: takes meeting notes, manages the communication between officers via Google Drive, and notifies members on the section email list about upcoming events.

- Treasurer: manages the section budget, applies for funding through the university, and oversees the taxes for the club.

- Outreach coordinator/chair: plans events which promote the club within the community; these include STEM related activities with local elementary and middle school students on campus, in their schools, and at the local museum.

- Event coordinator/chair: plan professional and social events for section members, both on and off campus. Professional events include resume workshops, career fair workshops, internship information panels, among others, all of which aim to prepare our members for the professional world. Social events include barbeques and outings to get coffee or ice cream off campus. The aim of these events is to connect women with other women across the engineering departments.

- Public relations officer: manages the section's social media accounts on Twitter and Facebook. She also promotes section events and activities through the page.

- Conference coordinator/chair: responsible for organizing and planning the trip to the SWE National Conference. This includes booking flights, making sure all necessary paperwork is completed for each attendee, managing the funding of the trip, and preparing attendees before departure for conference with information sessions.

- Alumni Associations: oversees finding and getting in touch with collegiate SWE alumni. The alumni can either be a previous student or can be a person in the professional work force who was in a SWE club as a student. The officer can ask alumni to come and speak with the club about their current jobs and life after college and whether or not they are still a member of SWE, as well as keep track of where students end up after college - whether that be continuing to get their masters or joining the workforce.

Some sections recently added the conference coordinator/chair to the officers.

\section{Small Section (KU/NMT)}

Small sections have approximately 5 7 basic officers and less than 20 members. Officer duties were defined as follows:

- President: the primary leader of the section. Focuses on initiating and maintaining the sections goals for each semester. The president is also responsible for running both section and officer meetings and communicating with professional and national SWE sections.

- Vice-president: assists the president (or other officers) as needed.

- Treasurer: in charge of the section funds. The treasurer's responsibilities include: maintaining and keeping track of the budget for each semester, assisting with 
documentation required by the institution's student government, and filing the financial report each year.

- Secretary: responsible for communication within the section as well as taking notes at meetings, sending out meeting minutes, and uploading meeting minutes on the sections' website and Facebook page.

- Public Relation officer: responsible for preparing flyers for SWE events and distributing them throughout campus.

\section{Tips for Smooth Officer Transition}

Officer transition has a significant impact on how smoothly the organization runs in the coming year. When the handoff does not go well, productivity in the Fall term is low, and activities for the year take a long time to be launched. For example, one year, at Cal State LA, the former Treasurer was not responsive to questions from the current Treasurer or other officers, resulting in the section being unable to determine how much funding remained and the source of such funding.

Officer transitions start with student-run elections in the Spring term. A description of each officer's duties is provided at a previous regular meeting and through email distribution lists. Candidates make speeches and students vote using an electronic anonymous ballot system. Once officers are elected, the transitional period begins. This process is described below for large, medium, and small sections.

\section{Large Section: (Cal Poly)}

The officer transition process plays a crucial role with passing down necessary information to incoming officers. CPSWE has been a collegiate section for decades and the officer transition process has been improved through the years.

CPSWE begins its transition process in their subcommittees. Legacy of leadership is fundamental for proper officer transition as in these subcommittees talent is sought for and growth is encouraged. Upon identifying individuals who showcase a great range of skills and passion for their event and project objectives, officers leading these subcommittees begin to mentor and praise these shining individuals before SWE elections and appointments are completed in late spring. Similar succession and mentorship is done as officers move from one of the four CPSWE cores to an executive core position and eventually to SWE President. This transition structure has greatly affected the growth of underclassmen females interested in SWE and has well fostered young talent into bright and ambitious women.

Longevity and retention are key to the success of CPSWE's legacy of leadership, so CPSWE emphasizes transparency on a position's job description and expectations. When an incoming officer is aware of their duties and their priority, CPSWE sees more SWE officers returning to fill higher positions. A comprehensive elections packet containing all officer positions and a thorough description is emailed to all members during the application process. Additionally, members are greatly encouraged to meet with current officers to learn more about the officer position on a personal level. 
One-on-one meeting and document binder: A third crucial component of officer transition is oneon-one and core group meetings. CPSWE holds two transition meetings held in mid-May where current officers meet one-on-one with the incoming officer. All past documents are kept on a Google Drive folder that is located in a specific folder for each core.

Retreat: At the beginning of the next academic year, the SWE Fall Retreat serves as a way to further transition into the officer position. Led by the VP of each core, new officers are able to see the whole picture, learn about responsibilities of other officers in their core, and enhance leadership skills.

Open communication: It is also important for the previous officer to be open to any questions the current officer may have throughout the year. Maintaining an open line of communication is essential.

\section{Medium Sections (CalStateLA/ MSU/WIT)}

Medium size sections handle leadership transition in a slightly different way.

Retreat: The retreat appears to be a fairly critical time for a smooth changing of the guard to take place. When officers do not show up to the retreat, there lays a heavy burden on the President to fill each of the officers in individually on their duties and roles and any procedural information that they might need. This then detracts from the President's ability to get events and activities off the ground smoothly at the start of the semester. At Cal State LA, in the summer after the new board is voted in, the newly incumbent officers and ex-incumbent officers gather for an offcampus overnight retreat for the previous officers to share past experiences and advice, and for the new officers to ask questions.

Documentation - binder: It is a common practice among sections to maintain a binder or portfolio to transfer useful information to the incoming officers. While in past years, the binder has tended to be a physical paper-based binder, many sections have more recently been using an e-binder, using google docs or shared documents, which is shared with the new officers when they are elected. In the "binder", there are separate folders for each position, as well as a document that provides the job description for each member of the executive board. The document also provides lessons learned from previous officers, as well as important contact information for faculty at the institute with whom the officer will be in frequent contact. Contacts provided include the faculty advisor, the student organization advisor assigned to the club through the institute, the professional SWE counselor, and others. The contact information provided changes depending on the position. There are important documents, like budget and accounting documentation, travel authorization forms for conference, and event flyers from current and previous years. Additionally, there is an overall SWE folder that contains all meeting notes, applications for funding, conference information, officer contact information, and other important yearly information organized by academic year that is shared between the officers and the faculty advisor. 
Strict accountability for officers to their duties: It appears that being strict about officer duties and having a way to replace someone who is neglecting their duties in office is a tricky balancing act, but when this is not in place or not executed, this can lead to many problems for the section. When everyone is well informed of what their duty is and they have had some mentorship from the previous officers, there is the huge benefit of teammates (other board members) being able to compensate and carry out tasks when a particular officer isn't able to attend meetings or perhaps isn't able to carry out their duties at some point in the year.

Officer election time: In the past most sections elect their office close to the end of the spring semester. The late timeframe of the elections during the end of the semester led to little communication between the new and outgoing officer, which led to difficulties in the next year. This was especially noticeable when the outgoing officer was a graduating senior, since getting answers to questions became difficult. Things as simple as passwords for the SWE email account, bank account information, when, where, and how events were planned, etc. have been lost during this transition and led to "reinventing the wheel" the following year.

In MSU, officer elections are now held about a month before classes end, allowing time for the new officers to meet with the previous officer to discuss the position. They typically go through the Google Drive folder and discuss what they wish they had done differently and what the new officer hopes to achieve in the position. In 2017, these discussions were incorporated into one of our social events at a coffee shop near campus to create a relaxed environment for this transition to occur.

WIT SWE club nominates and votes for the new executive board in the beginning of the spring semester. Once the new officers are decided upon, they shadow the current officers within the club. They are required to attend the executive board meetings that are held before the general body meeting each week and are trained in their positions by the current officer. By nominating and electing the new officers early in the spring semester, they can gain more experience with their positions. Current officers are encouraged to include the new officers when they are putting together events; for example, the new treasurer will work with the current treasurer on any budget reports and presentations, so that the new treasurer will understand the format of the reports and what information is important. The new officers eventually hold the last meeting of the year to try out what they have learned and to prepare them for the coming year.

With these key elements implemented, SWE sections at Cal State LA, MSU and WIT are the most active student clubs in their institutes. For example, WIT SWE club won the best student club twice in 4 years, they grew from 5 members in 2009 to around 25 members (paid and unpaid) attending SWE weekly meetings.

\section{Small Sections (KU/NMT)}

E-Binder: Similar to large and medium sections, the e-binder plays an important role in the transition. The students maintain transition documents, both for individual positions and for the section as a whole, saved to a Google Drive that the new officers can access. These documents include information on the responsibilities of the different officers, how to plan travel to the 
SWE Annual Conference, and how to run the major recurring events for the section. They also include lists of helpful resources, both on campus and within SWE.

Transition meeting: All new officers meet with current officers for an overall discussion of responsibilities. This general discussion elaborates on the interaction between the fellow officers and on the duties associated with each position. The current officers are then expected to have a one-on-one meeting with the upcoming officer who will be taking over their position. The current officers talk about where they left off with their goals for the year, and encourage new officers to build on those goals and complete them as necessary.

Election time: Similar to medium sections, elections are normally held in March, allowing for ample time for mentoring of each position.

Evidence of the effectiveness of NMT's current model is shown by the smoothness and the success of NMT SWE's re-occurring annual events. Officers are constantly updating their files, documenting everything, and learning from one another.

\section{Conclusions}

While specific means of communication vary from paper documentation to electronic binders and in-person hand-offs, the most critical component seen across all sections with successful transitions is that a plan has been established and continuously improved over time. The creation of templates or guiding documents for re-occurring events is also highly recommended. Further, there is one common trait shared by all six active SWE sections examined in this case study: While national SWE collegiate section bylaws requires only three elected officer positions, these institutions have all found more success in having more than this minimum number of office roles. The additional roles encourage younger student participation and lead to a natural model of leadership and transitional practices by the more experienced members.

\section{References:}

[1] M. D. Evans, D. M. Evans, L. D. Sherman, "Seven Keys to a Successful ASCE Student Chapter or Club: Guide for Student Leaders and Faculty Advisors", Journal of Professional Issues in Engineering Education and Practice, Vol. 127, Issue 2 (April 2001).

[2] C. Frieze and L. Blum, "Building an Effective Computer Science Student Organization: The Carnegie Mellon Women@SCS Action Plan”, SIGCSE Bulletin Vol. 34, No. 2, 2002 June.

[3] R. A. Reid and C.A. Tiltrum, "Eight Factors for Creating an Active Student Professional Society and How It Enhances the Engineering Curriculum", Proceedings of the 2003 American Society for Engineering Education Annual Conference \& Exposition, 2003.

[4] A. Craig, "Tips for effective Student Leader Transition", Campus Activities programming, May 2009, URL: http://www.trinitydc.edu/student-affairs/files/2013/06/8-Tips-for-EffectiveStudent-Leader-Transition.pdf, accessed 3/12/2018. 